\title{
Medium pH and nitrate concentration effects on accumulation of triacylglycerol in two members of the chlorophyta
}

\author{
Robert Gardner • Patrizia Peters • Brent Peyton • \\ Keith E. Cooksey
}

Received: 17 August 2010 / Revised and accepted: 16 November 2010/Published online: 3 December 2010

(C) Springer Science+Business Media B.V. 2010

\begin{abstract}
Algal-derived biodiesel is of particular interest because of several factors including: the potential for a nearcarbon-neutral life cycle, the prospective ability for algae to capture carbon dioxide generated from coal, and algae's high per acre yield potential. Our group and others have shown that in nitrogen limitation, and for a single species of Chlorella, a rise in culture medium $\mathrm{pH}$ yields triacylglycerol (TAG) accumulation. To solidify and expand on these triggers, the influence and interaction of $\mathrm{pH}$ and nitrogen concentration on lipid production was further investigated on Chlorophyceae Scenedesmus sp. and Coelastrella sp. Growth was monitored optically and TAG accumulation was monitored by Nile red fluorescence and confirmed by gas chromatography. Both organisms grew in all treatments and TAG accumulation was observed by two distinct conditions: high $\mathrm{pH}$ and nitrogen limitation. The Scenedesmus sp. was shown to grow and produce lipids to a larger degree in alkaliphilic conditions $(\mathrm{pH}>9)$ and was used to further investigate the interplay between TAG accumulation from high $\mathrm{pH}$ and/or nitrate depletion. Results given here indicate that TAG accumulation per cell, monitored by Nile red fluorescence, correlates with $\mathrm{pH}$ at the time of nitrate depletion.
\end{abstract}

Keywords Triacylglycerol $(\mathrm{TAG}) \cdot$ Fatty acid methyl ester (FAME) $\cdot$ Nile red fluorescence $\cdot$ Nile-red-specific fluorescence $\cdot$ Chlorophyta

\footnotetext{
R. Gardner · B. Peyton

Department of Chemical and Biological Engineering, Montana State University,

Bozeman, MT 59717, USA

P. Peters $\cdot$ K. E. Cooksey $(\bowtie)$

Department of Microbiology, Montana State University, Bozeman, MT 59717, USA

e-mail: umbkc@montana.edu
}

\section{Introduction}

Advancement in second generation renewable biofuels is of great importance environmentally, as well as strategically (Bilgen et al. 2004; Brown 2006; Dukes 2003; Schenk et al. 2008). Biodiesel and biojet fuel defined as fatty acid methyl esters (FAME) derived from plant, animal, or algal triacylglycerol (TAG), are attractive options as an alternative for portions of our current petroleum dependency. Hill's recent life cycle analysis suggests that biodiesel can yield $90 \%$ more energy than input requirements verses $25 \%$ for ethanol production (Hill et al. 2006). Additionally, this life cycle analysis noted less nitrogen, phosphorus, and pesticide release, and a $41 \%$ reduction in green house gas emission compared with ethanol. Furthermore, ethanol cannot be used in jet or diesel engines whereas fuel derived from TAGs can (Cunningham 2007). These benefits are further enhanced when precursor TAG is produced by microalgae as compared with plant sources. Microalgae can potentially have up to $80 \%$ of its dry weight as oil (this is much higher than we expect to achieve, $50 \%$ is far more likely) whereas plants such as soybean and oil palm have around 5\% oil content (Banerjee et al. 2002; Chisti 2007, 2008; Benemann and Oswald 1996; Sheehan et al. 1998). Furthermore, algal/plant-derived fuel is potentially nearcarbon neutral due to photosynthetic $\mathrm{CO}_{2}$ sequestration and typically microalgae exhibit high photon conversion efficiency which translates into increased biomass and ultimately, oil yield per acre (Schenk et al. 2008; Greenwell et al. 2010; Lardon et al. 2009).

An additional criterion mediating feasibility of a renewable fuel source is the ability to maintain stability of agricultural crop acreage. Because microalgae have considerable physiological diversity and can inhabit marine environments as well as hypersaline, brackish, and high alkalinity waters (Hu et al. 
2008), traditional food crop acreage can be avoided for use in biofuel production. Of particular interest is the use of alkaliphilic algae to circumvent potential limitations in largescale algal production. Specifically tailored high $\mathrm{pH}$ systems may decrease microbial contamination, allow for use of nonpotable water, and should facilitate higher mass transfer of carbon dioxide.

The work presented here compares growth and TAG accumulation in two different green algae, a Coelastrella sp. and a Scenedesmus sp. These algae differ from each other in that one was isolated from a near-neutral $\mathrm{pH}$ source, while the other was isolated from an alkaline stream $(\mathrm{pH}$ 8.7). Growth rates and TAG accumulation were evaluated at $\mathrm{pH}$ conditions ranging from 7-11. Guckert and Cooksey (1990) originally observed elevated $\mathrm{pH}$ leading to cellular TAG accumulation. However, their studies were done on a single species of Chlorella and their cultures were not incubated until nitrate depletion. Here we expand on that previous work concerning apparent $\mathrm{pH}$ effects on cellular TAG accumulation, which lends evidence to generalizing the $\mathrm{pH}$-induced TAG accumulation across Chlorophyta. Furthermore, separate and independent TAG accumulating factors are identified by incubating the high $\mathrm{pH}$ cultures until nitrate depletion occurs.

Combined pH-induced TAG accumulation and nitratedepletion-induced TAG accumulation was further investigated by studying high $\mathrm{pH}$ systems under different initial nitrate concentrations, advancing current knowledge of nitrate depletion effects (Li et al. 2008; Mandal and Mallick 2009; Ying Shen et al. 2009; Shen et al. 2010; Stephenson et al. 2010). Furthermore, the findings reported in this work were possible because medium $\mathrm{pH}$, nitrate, cellular density, and Nile red fluorescence were monitored over several weeks. This is a more detailed approach to studying growth and TAG accumulation in alga cultures and sets this work apart from other studies.

\section{Materials and Methods}

Organism isolation and culture Coelastrella sp. strain PC-3 (PC-3) was isolated from a CHLOR-1 culture obtained from the Hawaii Culture Collection (University of Hawaii, Honolulu, Hawaii). The CHLOR-1 culture was streaked onto Bold's basal medium plates and was discovered to comprise multiple morphotypes. Six strains were isolated (PC-2 to PC-7) and confirmed unialgal via SSU $18 \mathrm{~S}$ rDNA gene sequences. Phenotypic variation was further investigated by monitoring growth responses, $\mathrm{pH}$ shifts, and lipid accumulation. Genotypic variation was determined with repPCR-based genomic fingerprinting with random primers (OPA09, OBB04, and OPF07) (Fields and Justin, unpub- lished results). Based on physiological and fingerprinting responses, the six isolated strains were differentiated into three distinct groups. Molecular sequence alignment of PC3 (18S RNA, 1658 bp) showed 99\% homology with Coelastrella saipanensis.

Scenedesmus sp. strain WC-1 (WC-1) was isolated from an alkaline stream in Yellowstone National Park, USA ( $\mathrm{pH}$ 8.7) using agar plates (Bold's basal medium) and confirmed to be unialgal using SSU 18S RNA gene sequencing. Molecular sequencing of WC-1 revealed $100 \%$ alignment $(1,676 \mathrm{bp})$ with Scenedesmus obliquus X56103. Both organisms were checked for bacterial contamination by inoculation into Bold's basal medium supplemented with $0.05 \%$ yeast extract and $0.05 \%$ glucose and incubated in the dark.

Both PC-3 and WC-1 were grown on Bold's basal medium with $\mathrm{pH}$ adjusted to $\mathrm{pH} 6.8$ and 8.7, for PC-3 and WC-1, respectively (Nichols and Bold 1965). This medium was modified using $25 \mathrm{mM}$ biological $\mathrm{pH}$ buffers, including $N$-2-hydroxyethylpiperazine- $N{ }^{\prime}$-2-ethane-sulfonic acid (HEPES, pKa 7.4), 2-[N-cyclohexylamino]-ethanesulfonic acid (CHES, pKa 9.3), and 3-[cyclohexylamino]1-propane-sulfonic acid (CAPS, pKa 10.4) (Sigma-Aldrich), and the initial $\mathrm{pH}$ was set to the pka of the buffer. Biological cultures in triplicate were grown in batch on $100 \mathrm{~mL}$ medium in $250-\mathrm{mL}$ flasks shaken at $100 \mathrm{rpm}$ to keep cells in suspension. The conditions used were $27^{\circ} \mathrm{C}$ in a lighted incubator (Percival Scientific, 1-36LLVLX) under continuous illumination $\left(75 \mu \mathrm{mol}\right.$ photons $\left.\mathrm{m}^{-2} \mathrm{~s}^{-1}\right)$. The 250-mL flasks were covered with a stainless steel solid vent cap (Corning) for PC-3 or a modified vent cap in which the top area was bored out and covered with sterile wrap (Kimberly-Clark, 19-029-880) to increase gas transport for WC-1. Additionally, due to the increased gas transport in the modified caps, evaporation was shown to affect WC-1 experimental results significantly. Therefore, a sacrificial flask containing media was incubated alongside WC-1, which was weighed at each sample time to quantify evaporation. Filter sterilized ultrapure water $(18 \mathrm{M} \Omega)$ was added to the incubated WC-1 samples to offset evaporative losses. After initial findings from the $\mathrm{pH}-$ dependent experiments described above, WC-1 was grown in unbuffered and CAPS buffered Bold's basal medium with 90 and $360 \mathrm{mg} \mathrm{L}^{-1}$ nitrate (1.45 and $5.8 \mathrm{mM}$, respectively) to elucidate the individual effects of $\mathrm{pH}$ and nitrate depletion on TAG accumulation. Cell concentrations were counted directly using a hemocytometer with a minimum of 400 cells counted for statistical reliability. Micrographs of cell morphology were taken using a light microscope (Nikon eclipse E800) with an Infinity 2 color camera.

Analysis of media components Medium $\mathrm{pH}$ was measured on samples using a standard bench top $\mathrm{pH}$ meter. Concen- 
trations of phosphate, sulfate, and nitrate were measured by ion chromatography (IC) using an IonPac AS9-HC AnionExchange Column (Dionix) with a 9.0-mM sodium carbonate buffer set at a flow rate of $1.0 \mathrm{~mL} \mathrm{~min}$. Detection was performed using a CD20 conductivity detector (Dionix) at $21^{\circ} \mathrm{C}$, and IC data were analyzed on Dionix PeakNet 5.2 software. Phosphate and sulfate concentrations were measured by IC to confirm they were in excess during experimentation.

Lipid analysis Cellular TAG accumulation was estimated using the Nile red (9-diethylamino-5H-benzo $(\alpha)$ phenoxazine-5-one) (Kodak) fluorescence method developed by Cooksey et al. (1987). TAG accumulation was measured over time by removing $1 \mathrm{~mL}$ aliquots from cultures and diluting with 4-mL ultrapure $\mathrm{H}_{2} \mathrm{O}$ before assaying directly with Nile red $\left(20 \mu \mathrm{L}\right.$ from $250 \mu \mathrm{L} \mathrm{mL}^{-1}$ in acetone). Nile red fluorescence was quantified on a microplate reader (Bio-Tek instruments Inc.) utilizing 480/580 nm excitation/ emission filters. A baseline sensitivity setting of 75 was experimentally determined to maximize the signal-to-noise ratio while ensuring excess span range to accommodate fluorescent level changes over 10,000 units. Black-walled 96-well plates, to minimize fluorescence spillover, were loaded with $200 \mu \mathrm{L}$ of sample. Unstained samples were used for background medium and cellular autofluorescence correction. Cooksey et al. (1987) showed that the Nile red intensity shifts with time for different algal strains. This was recently reconfirmed by Elsey et al. (2007). Therefore, PC-3 and WC-1 Nile red fluorescence was measured over time to determine that measurement times of $30 \mathrm{~min}$ and 60 min were optimum for PC-3 and WC-1, respectively. These assay times were used for the Nile red assay throughout the experiments. Nile-red-specific fluorescence was calculated by dividing the Nile red fluorescence signal by the cellular density and then scaling with 10,000 to yield numbers ranging from $0-100$; the scaling factor was simply chosen to avoid decimal numbers.

Cells were harvested at the end of incubation by centrifugation $(4,000 \times g$ for $10 \mathrm{~min})$ and filtered using $1 \mu \mathrm{m}$ glass fiber filters (Fischer Scientific) to collect the biomass. Algal cells were dried, approximately $18 \mathrm{~h}$, on the filter in a $60^{\circ} \mathrm{C}$ oven until the filter weight was constant. Dry cell weight yields were calculated prior to lipid extraction by subtracting the dry weight of the clean filter from the oven dried weight of the filter with biomass. Algal TAG was extracted using a 1:1:1 chloroform/hexane/ tetrahydrofuran triple solvent extraction technique (Barney, personal communication). Dry cell mass $(\sim 100 \mathrm{mg})$ was loaded into a glass test tube containing $5 \mathrm{~mL}$ of the triple solvent solution. The biomass/solvent mixture was sonicated three times in $10 \mathrm{~s}$ increments and was centrifuged $(1,380 \times g)$ for approximately $1 \mathrm{~min}$, after which the solvent was collected in an Ichem style bottle. Another $5 \mathrm{~mL}$ triple solvent was added to the biomass, and the sonication, centrifugation, and solvent collection steps were repeated. After three successive rounds of extraction, the final volume in the Ichem bottle was brought to $15 \mathrm{~mL}$ with the triple solvent mixture. From the $15-\mathrm{mL}$ extract, $1 \mathrm{~mL}$ was dispensed into a $1.5-\mathrm{mL}$ autosampler vial with screw cap and a Teflon septum. To this $1 \mathrm{~mL}, 10-\mu \mathrm{L}$ octacosane (10 $\mathrm{mg}$ in $1-\mathrm{mL}$ triple solvent) was added as an internal standard and $50-\mu \mathrm{L} N$-methyl- $N$-(trimethylsilyl)trifluoroacetamide (MSTFA; (Fisher) was added as a silylation agent. MSTFA is trimethylsilyl donor which replaces labile hydrogen atoms on the carboxyl terminus of free fatty acids with $\mathrm{a}-\mathrm{Si}\left(\mathrm{CH}_{3}\right)_{3}$ group. These silylated samples were analyzed on gas chromatograph using $1-\mu \mathrm{L}$ injections (GC), flame ionization detection (GC-2010 Shimadzu) Column temperature was increased from $60^{\circ} \mathrm{C}$ to $370^{\circ} \mathrm{C}$ at a rate of $10^{\circ} \mathrm{C} \mathrm{min}^{-1}$ with a $60^{\circ} \mathrm{C}$ initial injection temperature. Helium was used as the carrier gas and column pressure and flow were $33.3 \mathrm{kPa}$ and $2.53 \mathrm{~mL}$ $\mathrm{min}^{-1}$, respectively. The column used was a $10 \mathrm{~m}$ (fused silica) RTX biodiesel (Restek) which has a film thickness of $0.1 \mu \mathrm{m}$. This GC method allows for quantification of hydrocarbons, free fatty acids, fatty acid methyl esters, monoacylglycerol, diacylglycerol, and triacylglycerol in a single analysis. TAG calibration curves were constructed using triolein and tripalmitin such that the peak areas, for each respective standard, were combined for quantification, $r^{2}>0.99$. The resulting chromatograms showed multiple peaks (three or four primary peaks and more secondary peaks) in the TAG retention time frame (28-34 min). This approach incorporated signal from TAG with variable fatty acid composition.

To identify individual free fatty acids and hydrocarbons of the cultures, $15-\mathrm{mL}$ extract was concentrated to $5 \mathrm{~mL}$ in an argon stream. One milliliter was removed and $10-\mu \mathrm{L}$ octacosane was added as internal standard and analyzed directly with $1-\mu \mathrm{L}$ injections on a $\mathrm{GC}$ mass spectrometer (Shimadzu, GCMS-QP20105) where the temperature was ramped at $10^{\circ} \mathrm{C} \mathrm{min}^{-1}$ from $60^{\circ} \mathrm{C}$ to $340^{\circ} \mathrm{C}$, the ion source temperature was $200^{\circ} \mathrm{C}$. The same $10 \mathrm{~m}$ (fused silica) RTX biodiesel (Restek) as described above was used with a column pressure of $149.8 \mathrm{kPa}$ and total flow of $28.5 \mathrm{~mL} \mathrm{~min}^{-1}$.

To identify the primary fatty acid constituents comprising the TAG molecules, the concentrated $5 \mathrm{~mL}$ extract was further concentrated until the triple solvent was fully volatilized, after which, the residue was resuspended in $1 \mathrm{~mL}$ methanol with $18-\mu \mathrm{L}$ concentrated sulfuric acid. This mixture was treated in a microwave reactor (Discovers CEM microwave), $150 \mathrm{~W}$, at $125^{\circ} \mathrm{C}$ for $20 \mathrm{~min}$ to transesterify the TAGs to FAMEs. One $\mathrm{mL}$ chloroform was added to the reaction mixture which was then washed 
with 2-3-mL deionized $\mathrm{H}_{2} \mathrm{O}$ and centrifuged. The aqueous phase was removed and another deionized $\mathrm{H}_{2} \mathrm{O}$ wash/ centrifuge step was performed. After which, the chloroform layer was removed and $10-\mu \mathrm{L}$ octacosane internal standard was added. GC with mass spectrometry as described above was used for FAME identification.

\section{Results and discussion}

Growth rates and TAG accumulation in variable $p H$ To investigate the apparent effect of $\mathrm{pH}$ on growth and TAG accumulation in PC-3 and $\mathrm{WC}-1$, growth was initiated in unbuffered (initial pH titrated to 6.8 and 8.7 for PC-3 and WC-1, respectively), HEPES (pKa 7.4), CHES (pKa 9.3), and CAPS (pKa 10.4) buffered Bold's basal medium. The experimental protocol was designed to minimize variation between culture treatments, with the exception of $\mathrm{pH}$. However, some variables (e.g., light penetration into a growing culture) could not be controlled. Therefore, our results show strong correlations, but may not be exclusive to other effects.

As shown in Fig. 1, PC-3 and WC-1 grew in all treatments. Specifically, PC-3 grew over a 26-day incubation period and exhibited the highest stationary phase cell density in the $\mathrm{pH} 7.4$ buffered medium. PC-3 in the $\mathrm{pH} 10.3$ buffered media showed a 4-day lag before growth ensued, and reached a lower cell density than in the other buffer treatments. The rates of growth were similar for all medium treatments. In contrast, cell densities for WC-1 followed two trends, the $\mathrm{pH} 7.4$ and 9.3 buffered cultures exhibited the highest cell densities followed by unbuffered and the $\mathrm{pH} 10.3$ buffered media, which produced approximately half as many cells. Growth rates were similar for the different medium conditions. All cultures were monitored until late stationary growth when the green cultures yellowed, corresponding with $\mathrm{pH}$ elevation in the medium and/or nitrate depletion, and were at peak TAG accumulation times before the onset of cellular lipid degradation or utilization. PC-3 was originally collected from a freshwater ditch next to a construction site in Boulder, Colorado (SERI 1986). Here, PC-3 exhibited optimal growth in near-neutral systems which coincides with previous studies (Guckert and Cooksey 1990). Furthermore, growth of PC-3 was inhibited as the medium $\mathrm{pH}$ increased, especially in systems above $\mathrm{pH} 10$. In comparison, WC-1 was isolated from an alkaline stream $\left(\mathrm{pH} 8.7\right.$ and temperature of $\left.31.7^{\circ} \mathrm{C}\right)$ and is therefore different from other $S$. obliquus in that they usually are grown nearer to neutrality (Makulla 2000; Mandal and Mallick 2009; Yang and Gao 2003). WC-1 exhibited the highest cell numbers in the $\mathrm{pH} 7.4$ and 9.3 buffered system. Microscopic inspection of cultures revealed morphological changes between the various $\mathrm{pH}$ systems (Fig. 2 micrographs). During exponential growth under both $\mathrm{pH} 7.4$ and 9.3 buffered treatments, WC1 exhibited a typical Scenedesmus shape. However the pH 7.4 buffered cultures revealed many small four cell clusters where the individual cells were smaller. In contrast, the $\mathrm{pH} 9.3$ buffered cultures exhibited much larger cells with more individual or two-cell groupings; however there were also a significant number of four-cell groupings (Fig. 2c). Chemical composition of the growth medium, light characteristics (wavelengths), and predator levels has been shown to cause similar morphology changes in Scenedesmus species (Khlebovich and Degtyarev 2005; Pickett-Heaps and Staehelin 1975; Trainor et al. 1976; Cepák et al. 2006). In addition, the high $\mathrm{pH}$ cultures, unbuffered and the $\mathrm{pH} 10.3$ buffered (Fig. 2a, d, respectively), show much larger cells in irregular conformations. Inspection of these cells indicates delayed autospore release as evident by the cell maintaining a partial separation state for an extended time. This is further support of Guckert and Cooksey's hypothesis (Guckert and Cooksey 1990) that high $\mathrm{pH}$ caused a decrease in individual cell release from autospore, ultimately leading to TAG
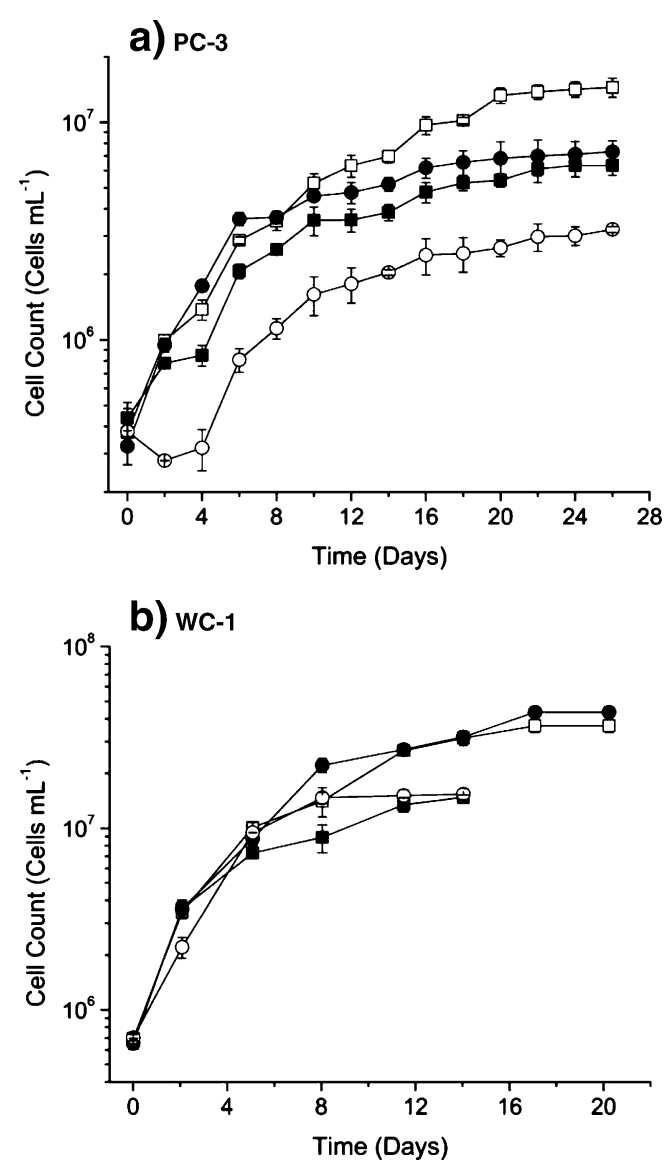

Fig. 1 Average cell density and standard deviation of PC-3 (a) and $W C-1$ (b) over the batch culture incubation. Growth was maintained in unbuffered (filled squares), HEPES buffered (empty squares) pKa 7.4, CHES buffered (filled circles) pKa 9.3, and CAPS buffered (empty circles) pKa 10.4 Bold's basal medium; $n=3$ 

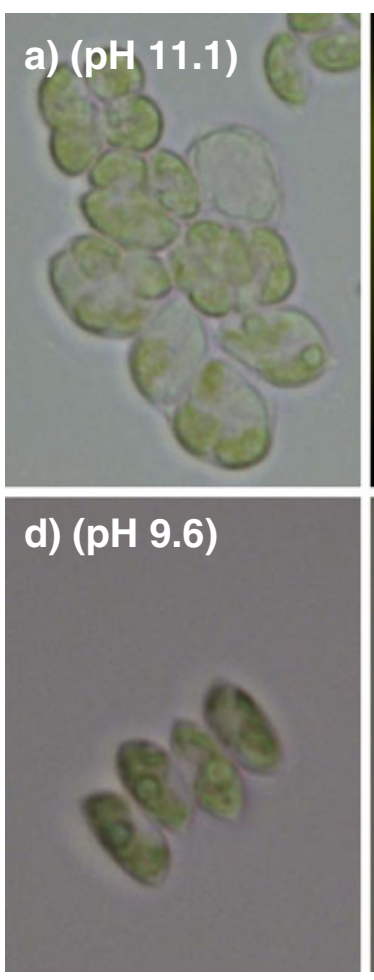
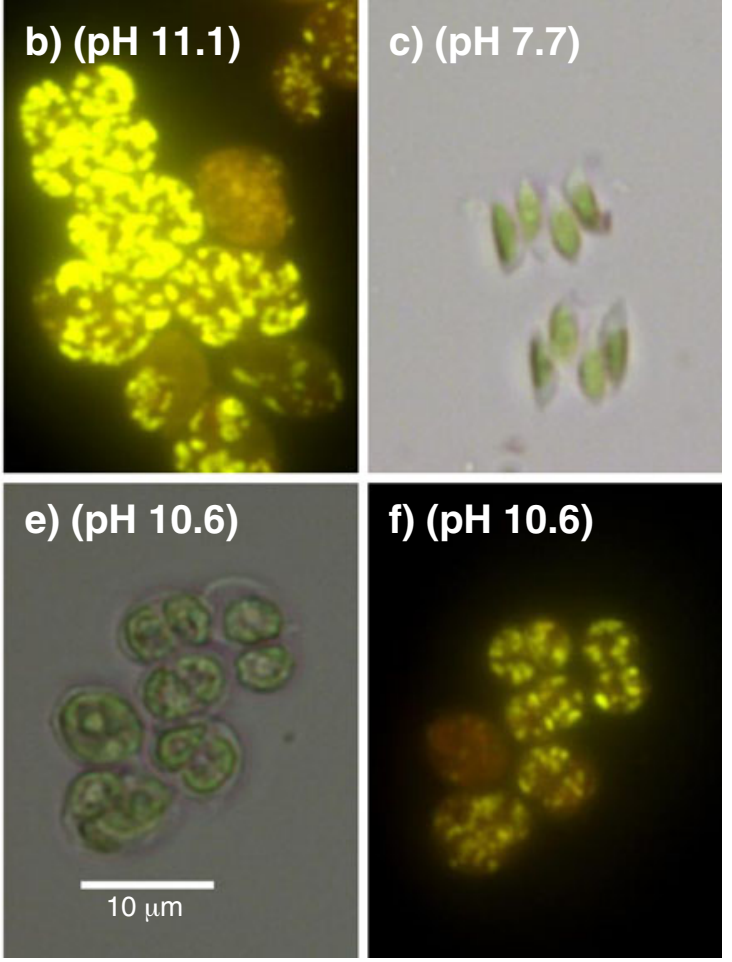

Fig. 2 Micrographs detailing morphology changes during growth and $\mathrm{pH}$-induced TAG accumulation shown by Nile red fluorescence of WC-1. Note the typical appearance of a Scenedesmus sp. growth at neutral $\mathrm{pH}(\mathbf{c})$ and the larger cellular conformation shown at higher $\mathrm{pH}$ values (a, b, d-f). Unbuffered (a), Nile red fluorescence of unbuffered culture (b) both had $\mathrm{pH} 11.1$ when micrographed, HEPES buffered (c) pH 7.7, CHES buffered (d) pH 9.6, and CAPS buffered (e) with Nile red fluorescence of CAPS buffered (f) pH 10.6 Bold's basal medium accumulation, originally investigated with Chlorella CHLOR-1.

Nile red fluorescence has been correlated to cellular TAG concentrations (Cooksey et al. 1987; Elsey et al. 2007; Guckert and Cooksey 1990), and the Nile red fluorescence of PC-3 is shown in Fig. 3a. Specifically, the $\mathrm{pH} 10.3$ buffered system, which maintained $\mathrm{pH}$ around 10 throughout the 26-day experiment, began to show elevated fluorescence around 4 days. This coincides with the lag period observed in Fig. 1, and we correlate this increased fluorescence with the high $\mathrm{pH}$. After 9 days, the apparent $\mathrm{pH}$-induced fluorescence response remained approximately constant at an intensity level near 550 units until the experiment concluded. Similarly, the unbuffered system began to exhibit an apparent $\mathrm{pH}$-induced increase in fluorescence around 16 and 18 days after the $\mathrm{pH}$ of the system reached an elevated level $(\mathrm{pH} 10)$ at 12 days, as shown in Fig. 3b. Initially the $\mathrm{pH}$ for the unbuffered system was set to $\mathrm{pH} 6.8$, and after inoculation shifted to $\mathrm{pH} 6.4$ at 0 day. However, with culture incubations the $\mathrm{pH}$ increases, possibly due to the dissolved $\mathrm{CO}_{2}$ being utilized for photosynthesis. The $\mathrm{pH}$ reaches 10 at 12 days, which would favor $\mathrm{HCO}_{3}{ }^{-}$as the primary dissolved inorganic carbon species. This lends evidence toward the cultures utilizing $\mathrm{HCO}_{3}{ }^{-}$as a carbon source, and also hints at the possibility that lack of dissolved $\mathrm{CO}_{2}$ could be the cause of TAG accumulation. However, the exact mechanism of $\mathrm{pH}-$ induced TAG accumulation is not known, and may not be directly attributed to hydrogen ion concentration. Herein we refer to the $\mathrm{pH}$-induced TAG accumulation effect in an apparent manner; future molecular experimentation will give insight into the exact mechanism.

Additionally, as shown in Fig. 3c, nitrate becomes depleted in the unbuffered system at 22 days and after which the elevated fluorescence response in the unbuffered system is correlated to both high $\mathrm{pH}$ and nitrate depletion. However, increased fluorescence up to and including 22 days is correlated to only $\mathrm{pH}$-induced TAG accumulation. Nitrate depletion was not reached in the $\mathrm{pH} 10.3$ buffered system until after 27 days. Comparison of Fig. 3ac show that the $\mathrm{pH} 7.4$ and 9.3 buffered cultures did not reach elevated $\mathrm{pH}(\mathrm{pH}>10)$, and no increase in fluorescence was observed before the slight increase observed after the nitrate was depleted at 18 days. This response was correlated to nitrate depletion.

The Nile red fluorescence of WC-1 is shown in Fig. 3d. The $\mathrm{pH} 10.3$ buffered system begins to exhibit elevated fluorescence response as early as 2 days and continued to show elevated Nile red fluorescence through 14 days. The $\mathrm{pH}$ in the $\mathrm{pH} 10.3$ buffered medium had a small amount of 
Fig. 3 Average and standard deviation of Nile red fluorescence intensity (a and $\mathbf{d}$ ), nitrate concentration (b and $\mathbf{e}$ ), and medium $\mathrm{pH}$ ( $\mathbf{c}$ and $\mathbf{f})$ of batch culture PC-3 (a-c) and WC-1 $(\mathbf{d}-\mathbf{f})$. Growth was maintained in unbuffered (filled squares), HEPES buffered (empty squares) pKa 7.4, CHES buffered (filled circles) pKa 9.3, and CAPS buffered (empty circles) pKa 10.4 Bold's basal medium; $n=3$
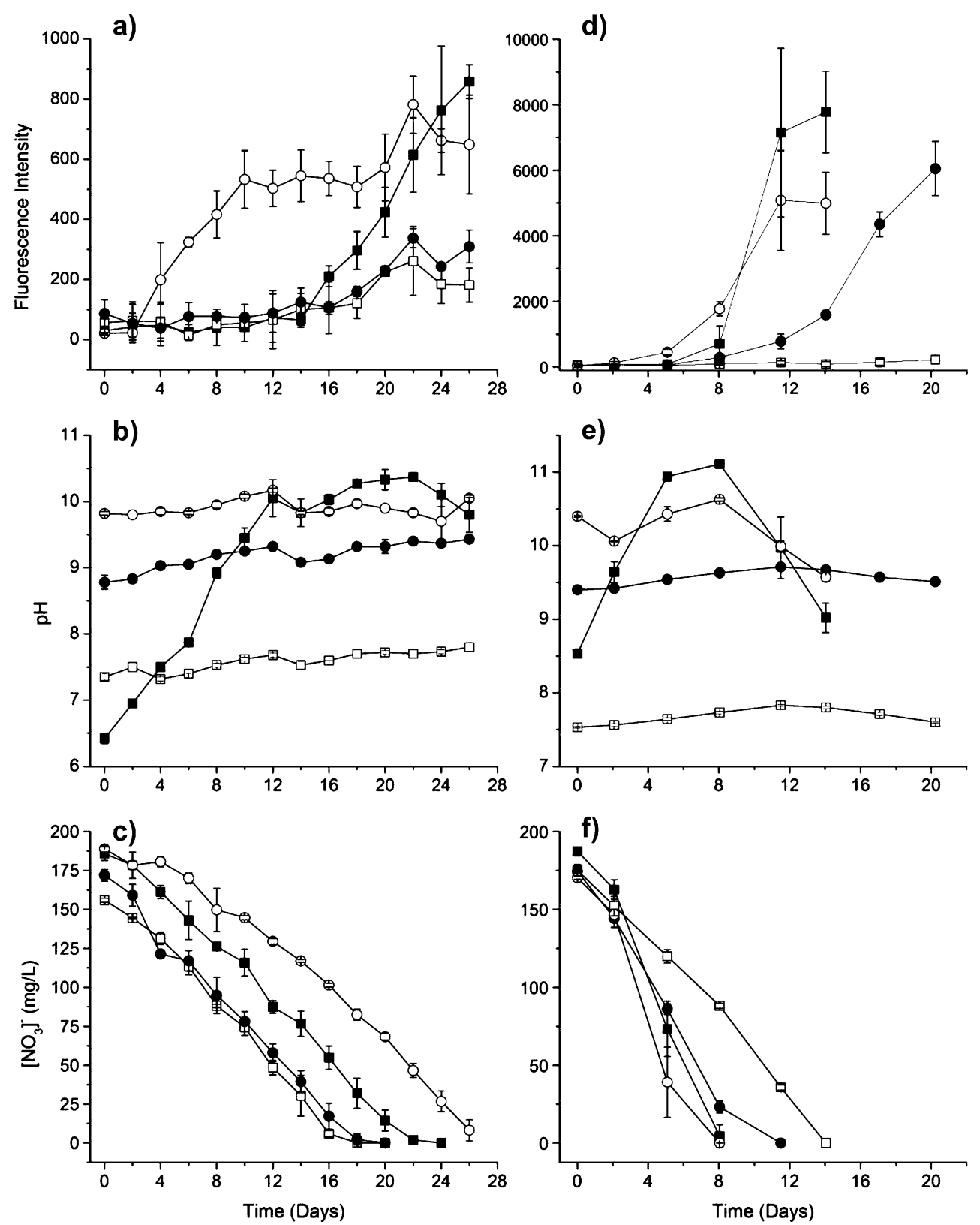

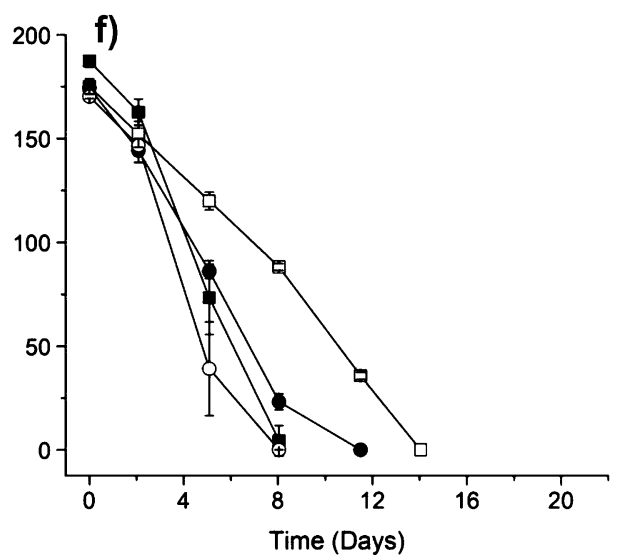

fluctuation (Fig. 3e), but maintained $\mathrm{pH}$ around 10.5 until 8 days. Therefore, the increase in Nile red fluorescence until 8 days is correlated to $\mathrm{pH}$-induced TAG accumulation. Furthermore as shown in Fig. 3f, nitrate became depleted for the unbuffered and the $\mathrm{pH} 10.3$ buffered media after 8 days. Therefore, the further elevation of fluorescence response after 8 days is correlated to combined $\mathrm{pH}$-induced and nitrate-depletion-induced TAG accumulation in the medium. Similarly, the unbuffered system shows increased fluorescence from 8 days through 14 days. Here again, increased $\mathrm{pH}$ is reached around 5 days and nitrate becomes depleted at 8 days (Fig. 3e, f). Therefore, Nile red fluorescence observed in the unbuffered system at 8 days is correlated to $\mathrm{pH}$-induced TAG accumulation and the subsequent increase in fluorescence after 8 days is correlated both $\mathrm{pH}$-induced and nitrate deficiency in the medium. Also demonstrated in Fig. 3e, $\mathrm{f}$ is the constant $\mathrm{pH}$ held for the $\mathrm{pH} 7.4$ and 9.3 buffered media, where nitrate was depleted at 14 and 9 days for the $\mathrm{pH} 7.4$ and 9.3 buffered cultures, respectively. The $\mathrm{pH} 9.3$ buffered cultures did not show any significant fluorescence response until 11 days, and after which there was an elevated fluorescence response until the end of the experiment. This fluorescence response is correlated to nitrate deficiency, as high $\mathrm{pH}$ levels $(\mathrm{pH}>10)$ were not attained in this system. Importantly, the $\mathrm{pH} 7.4$ buffered systems did not show an increase in fluorescence intensity, even after the system became nitrate depleted at 14 days. The smaller cells (Fig. 2b) observed at the lower $\mathrm{pH}$ did not accumulate TAG, even when nitrate depleted. 18S rRNA gene 
sequencing in WC-1 prior to inoculation confirmed that the culture was unialgal and not comprised of two species that could potentially differentiate with respect to $\mathrm{pH}$ leading to observed differences in cell morphological characteristics. Lipid accumulation has been reported in other nitrogen depletion studies using S. obliquus, however, $\mathrm{pH}$ changes or their effects were usually not reported (Gouveia and Oliveira 2009; Mandal and Mallick 2009).

Medium $p H$ effect on Nile red cell specific fluorescence The Nile red fluorescence response for PC-3 and WC-1 was further investigated by normalizing to cell density. This Nile-red-specific fluorescence gives insights into the TAG accumulation of an average algal cell under the culture conditions. As shown in Fig. 4, PC-3 shows higher specific fluorescence at higher $\mathrm{pH}$ values. Correlating to Fig. $3 \mathrm{a}$, the unbuffered and the $\mathrm{pH} 10.3$ buffered cultures exhibited increased specific fluorescence during high $\mathrm{pH}$ and also when high $\mathrm{pH}$ and nitrate depletion are combined. The pH 10.3 buffered cultures maintained a near-constant level
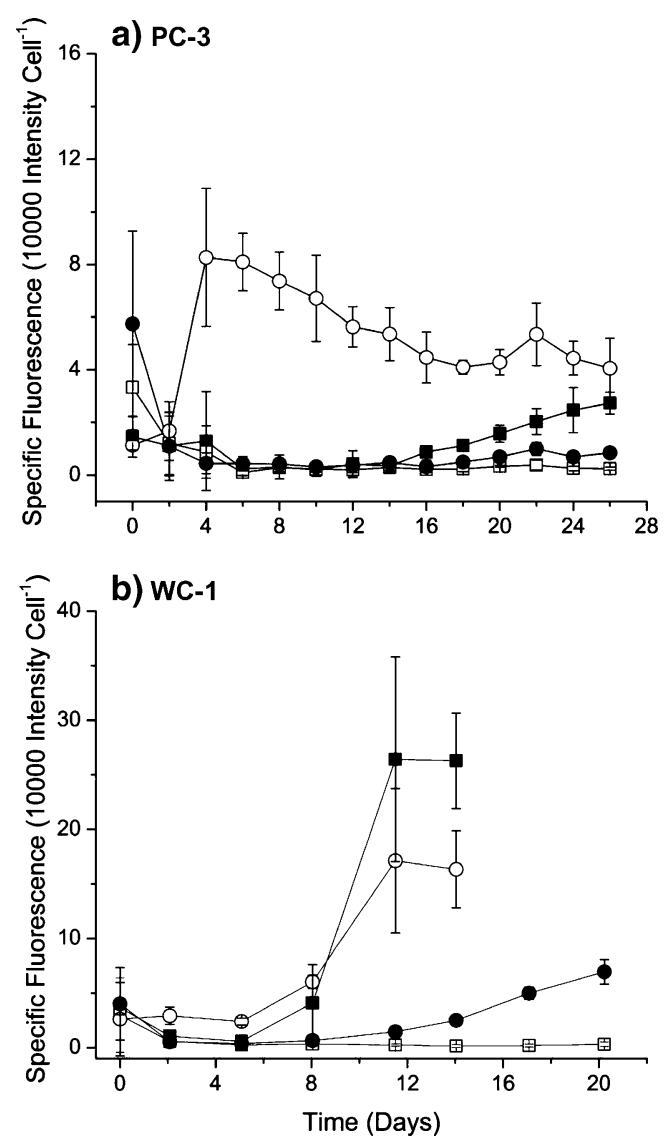

Fig. 4 Average and standard deviation of Nile red fluorescence per cell of PC-3 (a) and WC-1 (b) over the batch culture incubation. Growth was maintained in unbuffered (filled squares), HEPES buffered (empty squares) pKa 7.4, CHES buffered (filled circles) pKa 9.3, and CAPS buffered (empty squares) pKa 10.4 Bold's basal medium; $n=3$ from 4 days throughout the remainder of the experiment, with no significant difference between points. However, there was significant difference between the elevated level the unbuffered and the $\mathrm{pH} 10.3$ buffered cultures exhibited during $\mathrm{pH}$-induced TAG accumulation and the baseline values the other buffered systems were expressing. The pH 9.3 buffered cultures exhibited only a minor increase in specific fluorescence during nitrate depletion. In contrast, the $\mathrm{pH} 7.4$ buffered cultures did not show any increase in specific fluorescence. The Nile-red-specific fluorescence for WC-1 is shown in the bottom of Fig. 4. Correlating to Fig. 3d, the high $\mathrm{pH}$ unbuffered and $\mathrm{pH} 10.3$ buffered cultures show the highest levels of TAG accumulation. The pH 9.3 buffered medium shows increased specific fluorescence correlated to nitrate depletion, where as the $\mathrm{pH} 7.4$ buffered cultures did not show any increase in specific fluorescence throughout the experiment.

Table 1 compares growth and TAG accumulation characteristics for PC-3 and WC-1. The combined $\mathrm{pH}$ and nitrate depletion caused the highest final Nile-red-specific fluorescence responses in unbuffered and $\mathrm{pH} 10.3$ buffered cultures for both PC-3 and WC-1. Furthermore, GC analysis indicates the highest percent TAG (per dry cell weight) was also observed in the same unbuffered and $\mathrm{pH} 10.3$ buffered cultures. These same trends can be observed between specific fluorescence and percent TAG for each $\mathrm{pH}$ treatment. Additionally, the PC-3 and WC-1 samples were transesterified to show that for both PC-3 and WC-1, the primary fatty acids were 16:0 palmitic acid and 18:1 oleic acid. These are considered to be precursor fatty acids for membrane lipids and storage TAG lipids (Guckert and Cooksey 1990). It should be noted that specific fluorescence is reported on a per cell basis while percent of TAG was calculated on a dry biomass basis. These two correlate very well for the most part, but morphology changes (differently sized cells, Fig. 2) can alter the relationship between specific fluorescence and percent of TAG.

There has been no widely recognized standardized method for analyzing lipid production in microalgal studies (Griffiths and Harrison 2009). Historically, lipid concentrations have been quantified by extracting with two or three solvents used in combination or in series, with or without heat, sonication, or bead beating; after which the solvent was volatized. Percent lipid was calculated by one of two methods, (1) the weight of the extract (less solvent) was directly measured or (2) the samples were transesterified, so FAMEs could be quantified, and a three-toone ratio was assumed for FAME-to-TAG conversion (Guckert et al. 1988; Lee et al. 2010, 1998; Wiltshire et al. 2000; Bligh and Dyer 1959; Gouveia and Oliveira 2009; Mandal and Mallick 2009). The gravimetric determination inflates lipid measurements because other compounds are 
Table 1 Comparison of average cell density and dry cell weight with \% TAG and final Nile-red-specific fluorescence for both PC-3 and WC-1

\begin{tabular}{|c|c|c|c|c|c|c|c|}
\hline Organism & $\mathrm{pH}$ buffer & $\mathrm{pH}$ & $\begin{array}{l}\text { Initial }\left(\mathrm{NO}_{3}\right)^{-} \\
\left(\mathrm{mg} \mathrm{L}^{-1}\right)\end{array}$ & $\begin{array}{l}\text { Final cell density } \\
\left(\times 10^{7} \text { cells } \mathrm{mL}^{-1}\right)\end{array}$ & $\begin{array}{l}\text { Dry cell weight } \\
\left(\mathrm{g} \mathrm{L}^{-1}\right)^{\mathrm{a}}\end{array}$ & $\begin{array}{l}\% \text { TAG (gas } \\
\text { chromatography) }\end{array}$ & $\begin{array}{l}\text { Nile red intensity } \\
\text { cell }^{-1 \mathrm{~b}}\end{array}$ \\
\hline \multirow[t]{8}{*}{ WC-1 } & Unbuffered & $8.4-11.1$ & 90 & 1.92 & 0.83 & 9.3 & $16.9 \pm 2.0$ \\
\hline & Unbuffered & & $180^{\mathrm{c}}$ & 1.48 & 0.72 & 16.8 & $26.3 \pm 4.4$ \\
\hline & Unbuffered & & 360 & 3.50 & 1.56 & 8.6 & $14.1 \pm 0.7$ \\
\hline & HEPES & 7.5 & $180^{\mathrm{c}}$ & 3.66 & 0.97 & 0.6 & $0.3 \pm 0.2$ \\
\hline & CHES & 9.4 & $180^{\mathrm{c}}$ & 4.36 & 1.08 & 6.2 & $7.0 \pm 1.1$ \\
\hline & CAPS & $9.4-10.5$ & 90 & 2.61 & 1.00 & 3.1 & $6.3 \pm 0.9$ \\
\hline & CAPS & & $180^{\mathrm{c}}$ & 1.54 & 0.54 & 7.7 & $16.3 \pm 3.5$ \\
\hline & CAPS & & 360 & 4.23 & 1.60 & 7.4 & $13.5 \pm 1.2$ \\
\hline \multirow[t]{4}{*}{ PC-3 } & Unbuffered & $6.5-10$ & $180^{\mathrm{c}}$ & 0.63 & 0.71 & 0.6 & $2.7 \pm 0.4$ \\
\hline & HEPES & 7.5 & $180^{\mathrm{c}}$ & 1.45 & 0.86 & 0.1 & $0.3 \pm 0.1$ \\
\hline & CHES & 9.0 & $180^{\mathrm{c}}$ & 0.73 & 0.96 & 0.1 & $0.8 \pm 0.1$ \\
\hline & CAPS & $9.7-10.0$ & $180^{\mathrm{c}}$ & 0.32 & 0.71 & 0.6 & $4.1 \pm 1.1$ \\
\hline
\end{tabular}

Nitrate variation analysis was done on WC-1 with unbuffered and CAPS buffered Bold's basal medium at 90 and $360 \mathrm{mg} \mathrm{L}^{-1}$ nitrate; $n=3$

${ }^{a}$ Determined gravimetrically with filtered samples dried at $60^{\circ} \mathrm{C}$

${ }^{\mathrm{b}}$ Calculated by fluorescence signal/cell density $\times 10,000$ (scaling factor)

${ }^{\mathrm{c}}$ Standard concentration in Bold's basal medium

extracted (e.g., chlorophyll) that do not actually contribute to a true "biofuel potential". Furthermore, transesterified FAME-to-TAG conversion fails to account for free fatty acids or hydrocarbons that may be in the extract. Here, we have analyzed extracts directly by GC allowing analysis of secondary constituents including free fatty acids, hydrocarbons, monoacylglycerol, diacylglycerol, and other nutraceuticals (e.g., omega-3 fatty acids), as well as quantifying the amount of TAG directly. Percent of TAG is a more accurate quantification of the neutral lipids capable of being converted to biofuel (biofuel potential), however this percentage is smaller than total extractable lipid levels previously reported in literature (Griffiths and Harrison 2009; Chisti 2007). Thus, a TAG concentration of $16.8 \%$, as observed in WC-1 when cultivated in unbuffered medium (Table 1), is a reasonably high lipid concentration and more accurately represents the true biofuel potential than a gravimetrically determined total lipids value.

Our results show PC-3 grows best at neutral $\mathrm{pH}$ while WC-1 prefers alkaline $\mathrm{pH}$. Both Chlorophytes exhibit evidence of the previously described $\mathrm{pH}$-induced TAG accumulation (Guckert and Cooksey 1990). Here, we build on those findings by observing amplified cellular TAG accumulation in the alkaliphilic WC-1 when high $\mathrm{pH}$ and nitrate depletion are combined. This was not observed in the original $\mathrm{pH}$-dependent investigation because experiments were not allowed to proceed until complete nitrate utilization (Guckert and Cooksey 1990). It is noted that TAG accumulation levels are lower for high $\mathrm{pH}$ conditions alone compared with nitrate-depletion-induced TAG accu- mulation, however total TAG accumulation is greater when these two triggers perform in concert. In addition, the total experimentation time for growing a culture and inducing TAG accumulation was significantly shortened by using both high $\mathrm{pH}$ and nitrate depletion. We feel that greater TAG accumulation and shorter culture time is industrially relevant and this study offers insight into mass production schemes.

Nile red fluorescence responses and \% TAG in both PC3 and $\mathrm{WC}-1$ indicate there was a higher TAG accumulation in WC-1 when compared with PC-3. However, the gas transport was enhanced in the WC-1 cultures due to the use of cloth coverings on the culture flasks. Additional studies have been conducted which show PC-3 grows with a shorter generation time and to a greater extent under the cloth caps, but continued to exhibit lower Nile red total and specific fluorescence as compared with WC-1 (unpublished data). In this study, we used WC-1 and PC-3 to demonstrate the generality of the $\mathrm{pH}$-induced TAG accumulation effect, not necessarily to compare the two organisms. Also because alkaliphilic environments have the potential to minimize microbial (especially algal) contamination and competition, along with a increasing total inorganic carbon as $\mathrm{pH}$ is increased (Stumm and Morgan 1996), the alkaliphilic WC1 chlorophyte was our focus for additional investigations quantifying TAG accumulation in response to combined high $\mathrm{pH}$ and nitrate depletion. Furthermore, at $\mathrm{pH} 8-11$ the dominant form of inorganic carbon is bicarbonate and Scenedesmus has been shown utilize carbon in this form (Thielmann et al. 1990). 
Growth and TAG accumulation in high medium $\mathrm{pH}$ with different initial nitrate concentrations Combined $\mathrm{pH}-$ and nitrate-depletion-induced TAG accumulation was further analyzed by observing growth and percent TAG accumulation in WC-1 with initial nitrate concentrations of 90 and $360 \mathrm{mg} \mathrm{L}^{-1}$ using unbuffered and $\mathrm{pH} 10.3$ buffered Bold's basal medium (Fig. 5). WC-1 grew in all nitrate concentrations with both unbuffered and $\mathrm{pH} 10.3$ buffered medium. Growth indicated lower cell densities in unmodified medium nitrate concentrations $\left(180 \mathrm{mg} \mathrm{L}^{-1}\right)$. Growth optima with respect to nitrate concentration have been previously observed (Li et al. 2008; Stephenson et al. 2010) and may be attributed to the elevated $\mathrm{pH}$ and TAG accumulation observed under this nitrate concentration. Also, cell densities in the $\mathrm{pH} 10.3$ buffered systems were higher at all nitrate concentrations than the unbuffered systems. This indicates a $\mathrm{pH}$ optimum for cell growth for WC-1 at an approximate $\mathrm{pH}$ of 10.5 .

Figure 6 shows the average Nile red fluorescence (a and d), medium $\mathrm{pH}$ (b and e), and nitrate concentration ( $\mathrm{c}$ and $\mathrm{f}$ ) for WC-1 in unbuffered $(\mathrm{a}-\mathrm{c})$ and $\mathrm{pH} 10.3$ buffered $(\mathrm{d}-\mathrm{f})$
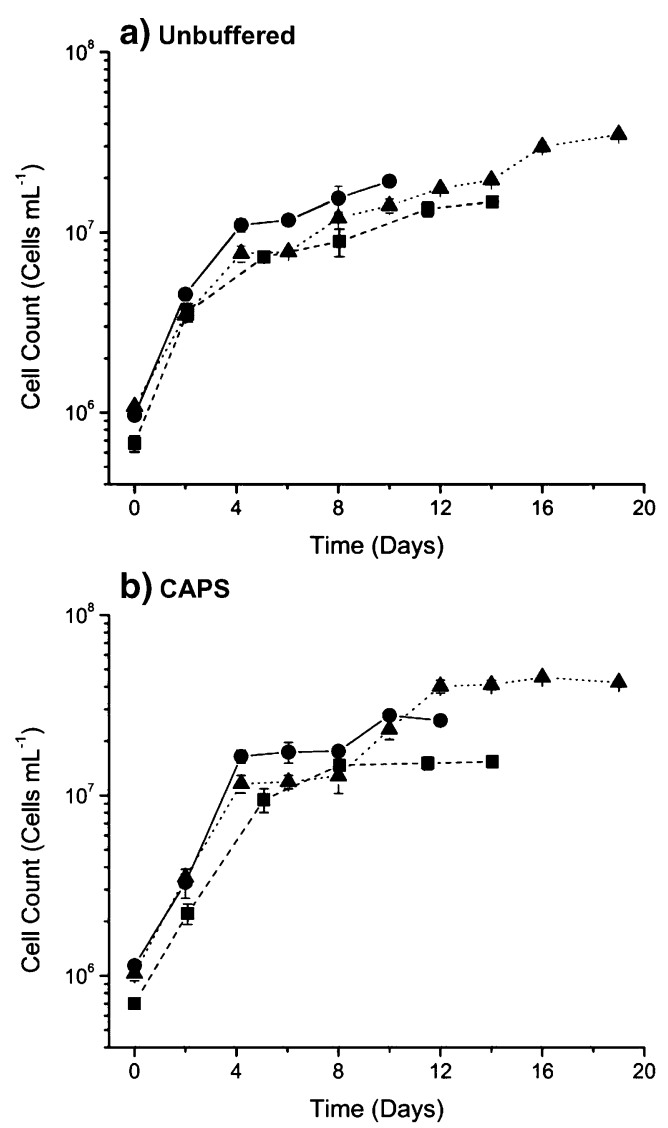

Fig. 5 Average and standard deviation of WC-1 cell density in unbuffered (a) and CAPS buffered (b) Bold's basal medium initially containing $90 \mathrm{mg} \mathrm{L}^{-1}$ (solid line, filled circles), $180 \mathrm{mg} \mathrm{L}^{-1}$ (dashed line, filled squares), and $360 \mathrm{mg} \mathrm{L}^{-1}$ (dotted line, filled triangles) nitrate; $n=3$ media. The Nile red fluorescence for unbuffered and pH 10.3 buffered cultures show TAG accumulation correlated with cultures that reached high $\mathrm{pH}$ (Fig. 6b, e). The apparent $\mathrm{pH}$-induced Nile red fluorescence increase was observed at 4 days until the respective cultures become nitrate depleted at 4, 8, and 12 days (Fig. 6c, f) in 90, 180, and $360 \mathrm{mg} \mathrm{L}^{-1}$ nitrate, respectively, for both unbuffered and CAPS buffered cultures. When the systems became nitrate depleted, increased Nile red fluorescence was correlated with combined high $\mathrm{pH}$ and nitrate depletion. The cultures reached highest fluorescence responses at 8 , 12 , and 20 days for nitrate concentrations 90, 180, and $360 \mathrm{mg} \mathrm{L}^{-1}$, respectively in the unbuffered systems. Additionally, the 90,180 , and $360 \mathrm{mg} \mathrm{L}^{-1}$ nitrate in the $\mathrm{pH} 10.3$ buffered systems reached highest fluorescence response at 12,14 , and 20 days, respectively.

Medium $p H$ decrease after nitrate depletion WC-1 experiments show that the $\mathrm{pH}$ decreased after the media became nitrate limited (Figs. 3e, f and 6). When the culture medium became nitrate depleted, photosynthesis rates likely decreased allowing carbon dioxide to accumulate in the media, causing the medium $\mathrm{pH}$ to decrease (Stumm and Morgan 1996). Interestingly, when WC-1 was grown under unbuffered conditions with $360 \mathrm{mg} \mathrm{L}^{-1}$ nitrate (Fig. 6b), the $\mathrm{pH}$ increased to greater than $\mathrm{pH} 11$ by 5 days which inhibited culture growth and subsequently caused the $\mathrm{pH}$ to decrease due to $\mathrm{CO}_{2}$ accumulation. Once the $\mathrm{pH}$ had decreased to approximately 10.3, the culture rebounded and additional growth ensued which caused the $\mathrm{pH}$ to increase back to near $\mathrm{pH} 11$.

Combined medium $\mathrm{pH}$ and nitrate depletion effect on Nilered-specific fluorescence Figure 7 shows the specific fluorescence response for unbuffered (a) and the $\mathrm{pH} 10.3$ buffered (b) media. The \% TAG levels (from gas chromatography analysis) for these samples are given in Table 1 and there is excellent correlation to the observed Nile-red-specific fluorescence $\left(R^{2}=0.95\right)$. This high correlation between specific fluorescence and \% TAG would not be the case if Nile red fluorescence was $\mathrm{pH}$ dependent, also Nile red staining in acetone is a noninvasive technique that penetrates whole cells where internal $\mathrm{pH}$ is metabolically controlled. The specific fluorescence in Fig. 7 shows highest TAG accumulation correlating with combined high $\mathrm{pH}$ and nitrate depletion. Final values of specific fluorescence for the unbuffered 90 , and $360 \mathrm{mg} \mathrm{L}^{-1}$ nitrate cultures were 16.9 and 14.1, respectively, with $\mathrm{pH}$ reaching 10.9 for both at nitrate depletion. In contrast, the unbuffered $180 \mathrm{mg} \mathrm{L}^{-1}$ nitrate cultures reached a specific fluorescence level of 26.3 with a $\mathrm{pH}$ of 11.1 at nitrate depletion. Specific fluorescence in the $\mathrm{pH} 10.3$ buffered 90 , and $360 \mathrm{mg} \mathrm{L}^{-1}$ nitrate cultures were 6.3 and 13.5 , respectively with a $\mathrm{pH}$ of 10.5 and 10.7 at time of nitrate depletion. This is compared 
Fig. 6 Average and standard deviation of Nile red fluorescence intensity (a and d), $\mathrm{pH}$ (b and $\mathbf{e}$ ), and nitrate concentration (c and f) of WC-1 in unbuffered $(\mathbf{a}-\mathbf{c})$ and CAPS buffered $(\mathbf{d}-\mathbf{f})$ Bold's basal medium originally containing $90 \mathrm{mg} \mathrm{L}^{-1}$ (filled circles), $180 \mathrm{mg} \mathrm{L}^{-1}$ (filled squares), and $360 \mathrm{mg} \mathrm{L}^{-1}$ (filled triangles) nitrate; $n=3$
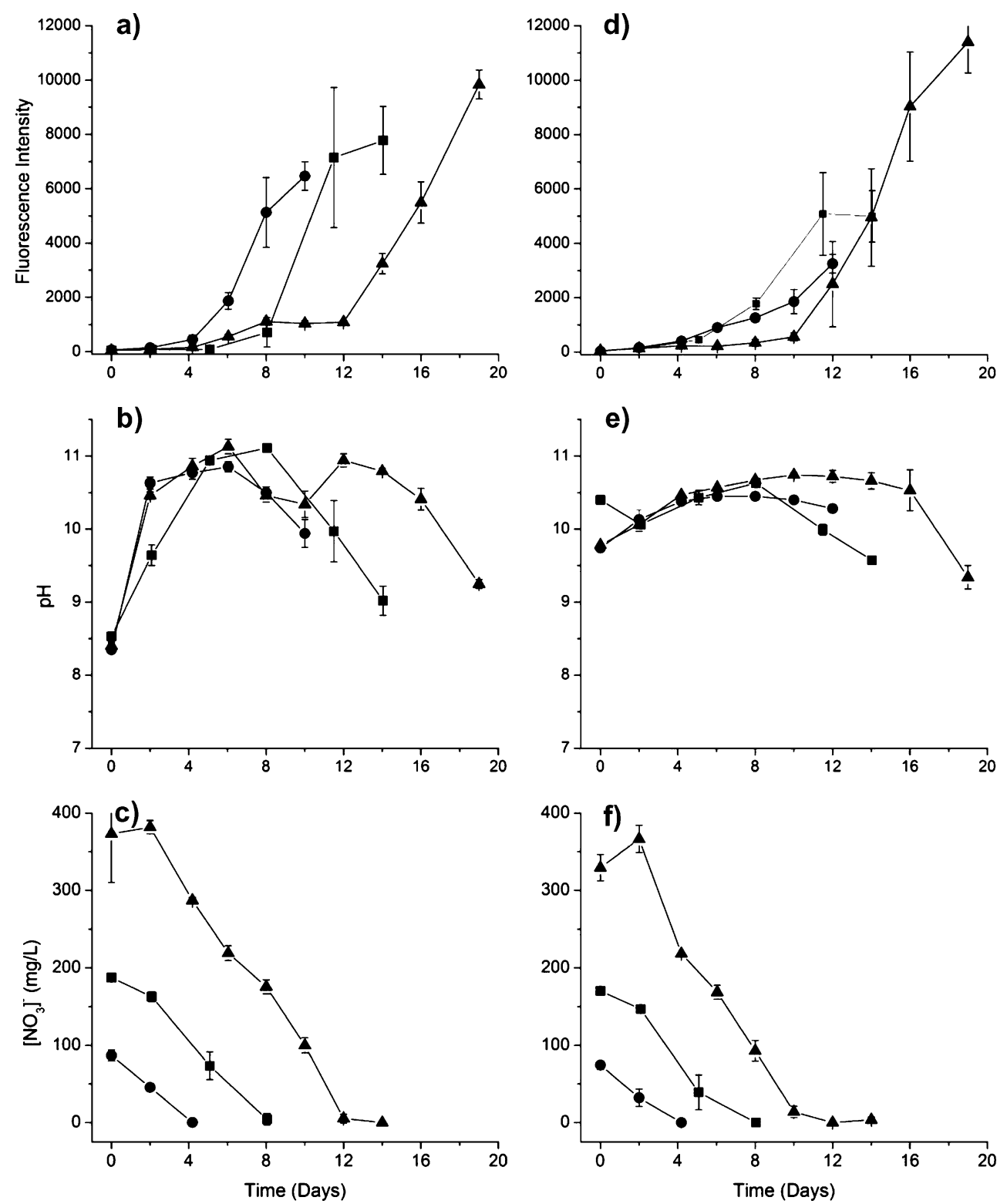

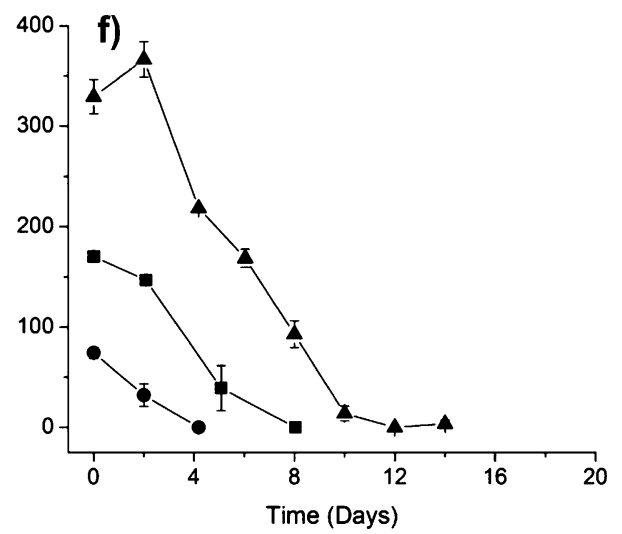

with the $\mathrm{pH} 10.3$ buffered $180 \mathrm{mg} \mathrm{L}^{-1}$ nitrate cultures, which reached 16.3 with a $\mathrm{pH} 10.6$ at nitrate depletion. For all WC1 culture conditions, Fig. 8 shows the specific fluorescence at the end of the experiments as a function of the $\mathrm{pH}$ at the time of nitrate depletion. These results indicate that the final TAG accumulation per cell correlates with $\mathrm{pH}$ at the time of nitrate depletion $\left(R^{2}=0.95\right.$ with exponential fit). To our knowledge, this is the first report of a two parameter TAG accumulation trigger, and we expect this to have a strong impact on industrial algal biodiesel production. Using this information, reactors or ponds should operate at an optimal growth $\mathrm{pH}$ until an appropriate algal density is obtained. Prior to nitrate depletion, the $\mathrm{pH}$ would be increased to trigger high TAG accumulation as the nitrate is depleted. Under these conditions, both environmental parameters work in concert to trigger TAG accumulation. Furthermore, we anticipate that other environmental parameter combinations will correlate with TAG accumulation, for example, temperature and nitrate depletion or $\mathrm{pH}$ and silica depletion for diatoms (Shifrin and Chisholm 1981). This finding demonstrates the importance of performing fundamental studies on algal strains that can be used for industrial applications.

Nile red fluorescence plateau during pH-only TAG accumulation Of additional interest is the constant Nile red fluorescence response and constant specific fluorescence response during the time when high $\mathrm{pH}$ was the only TAG accumulation inducing factor. This was observed between 8 and 12 days in the $360 \mathrm{mg} \mathrm{L}^{-1}$ nitrate cultures for both unbuffered and $\mathrm{pH} 10.3$ buffered cultures (Figs. 6a, $\mathrm{b}$, and $7 \mathrm{a}, \mathrm{b})$. Here, the $\mathrm{pH}$-induced fluorescence response begins at approximately 5 days (high $\mathrm{pH}$ attainment at 

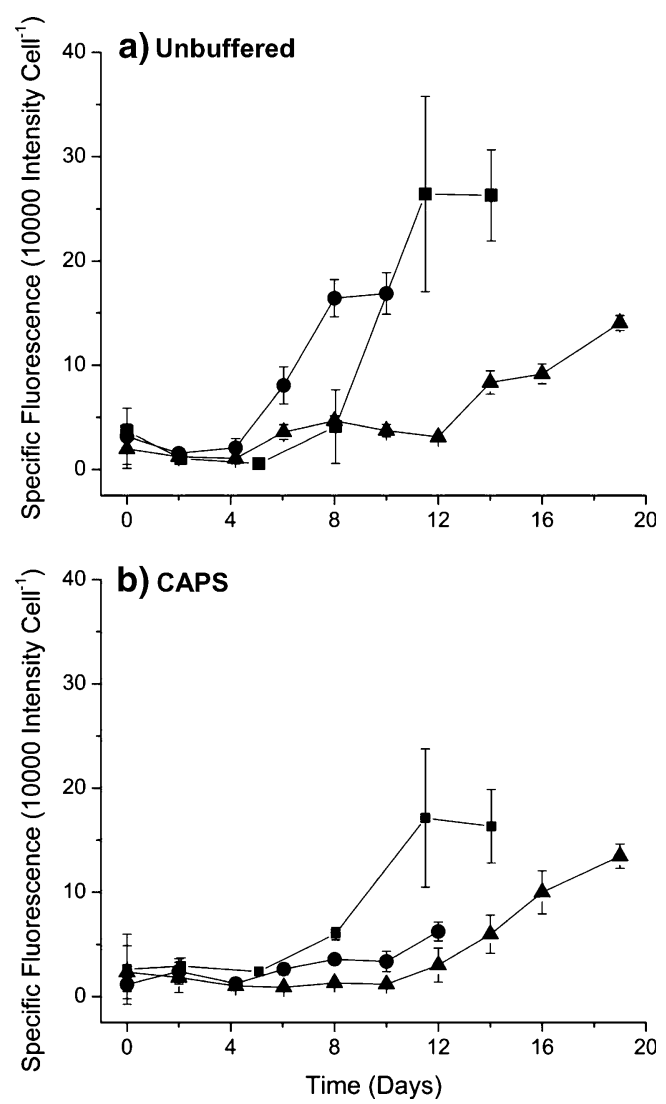

Fig. 7 Average and standard deviation of WC-1 Nile red fluorescence per cell in unbuffered (a) and CAPS buffered (b) Bold's basal medium originally containing $90 \mathrm{mg} \mathrm{L}^{-1}$ (filled circles), $180 \mathrm{mg} \mathrm{L}^{-1}$ (filled squares), and $360 \mathrm{mg} \mathrm{L}^{-1}$ (filled triangles) nitrate; $n=3$

2 days) and increases to a near-constant level when high $\mathrm{pH}$ is the only TAG accumulation inducing factor. Additionally, this correlates to the similar effect observed in Fig. 4a, albeit a much smaller response level, where the PC-3 $\mathrm{pH} 10.3$ buffered system maintained a constant level of TAG before nitrate became limited.

\section{Conclusions}

Two chlorophytes Scenedesmus sp. WC-1 and Coelastrella sp. PC-3 were analyzed in $\mathrm{pH}$ buffered systems to determine the effect of $\mathrm{pH}$ on growth and TAG lipid accumulation. PC-3 was originally isolated from nearneutral conditions and grew best in neutral HEPES buffered system (pka 7.4). In contrast, WC-1 was isolated from an alkaline creek in Yellowstone National Park and exhibited optimum growth in the CHES buffered system (pka 9.3).

Both unbuffered and CAPS buffered (pka 10.3) systems revealed early high apparent $\mathrm{pH}$-induced TAG accumulation measured as total Nile red fluorescence and specific fluorescence. Furthermore, the unbuffered and $\mathrm{pH} 10.3$ buffered systems revealed TAG accumulation correlated to

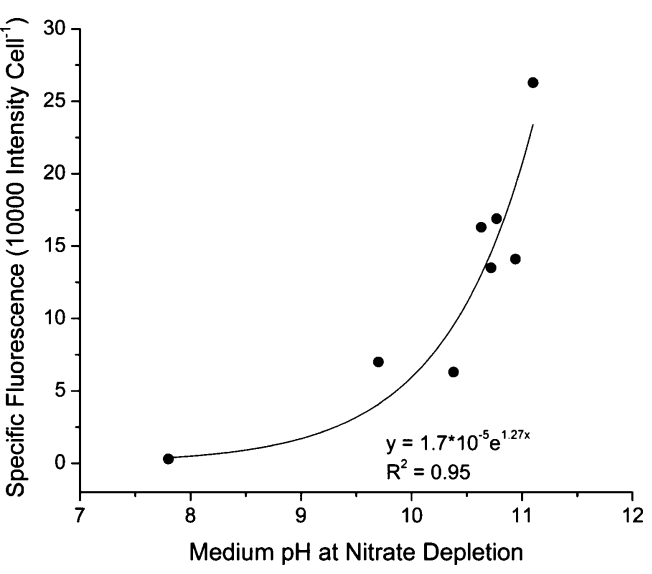

Fig. 8 Correlation of $\mathrm{pH}$ at the time of nitrate depletion, with the average Nile red fluorescence per cell, at the conclusion of the experiments, for all culture conditions of WC-1 in Bold's basal medium

both high $\mathrm{pH}$ and nitrate depletion conditions. The combined response was much stronger than either high $\mathrm{pH}$ - or nitrate-depletion-induced TAG accumulation independently. The $\mathrm{pH}$-induced response was confirmed with GC analysis, and supports results presented by Guckert and Cooksey (1990). Furthermore, this study revealed that both organisms maintained a near-constant TAG concentration during $\mathrm{pH}$-induced TAG accumulation until nitrate depletion. After nitrate depletion, the combined high $\mathrm{pH}$ and nitrate depletion caused the greatest TAG accumulation under all observed conditions, especially in the unbuffered systems. Finally, these results indicate that TAG accumulation per cell at the end of the experiments correlate exponentially with the $\mathrm{pH}$ at the time of nitrate depletion.

Financial disclosure/Acknowledgments The authors would like to thank Dr. Brett Barney and the Seefeldt lab group (Utah State University) for assistance with the gas chromatographic analyses and for technical support from the Montana State University Algal Biofuels Group, especially, Dr. Matthew Fields and Grant Justin for molecular fingerprinting work done on CHLOR-1 and PC-3. Also of special note is the $18 \mathrm{~S}$ rRNA gene sequence interrogations done by Seth D'Imperio and Rich Macur, along with instrumental support from the Montana State University Center for Biofilm Engineering. Funding was provided by the Air Force Office of Scientific Research (AFOSR grant FA9550-09-1-0243), US Department of Energy (Office of Biomass Production grant DE-FG36-08GO18161), and support for RG was provided by NSF IGERT Program in Geobiological Systems (DGE 0654336) at Montana State University.

\section{References}

Banerjee A, Sharma R, Chisti Y (2002) Botryococcus braunii: a renewable source of hydrocarbons and other chemicals. Crit Rev Biotechnol 22(3):245

Benemann J, Oswald W (1996) Systems and economic analysis of microalgae ponds for conversion of $\mathrm{CO}_{2}$ to biomass. Final report (other information: PBD: 21 Mar 1996). pp. 214 
Bilgen S, Kaygusuz K, Sari A (2004) Renewable energy for a clean and sustainable future. Energy Sources 26(12):1119-1129

Bligh E, Dyer W (1959) A rapid method of lipid extraction and purification. Can J Biochem Physiol 37(8):911-917

Brown L (2006) Plan b: Rescuing a planet under stress and a civilization in trouble. W.W. Norton Publishing, London

Cepák V, Přibyl P, Vítová M (2006) The effect of light color on the nucleocytoplasmic and chloroplast cycle of the green chlorococcal alga Scenedesmus obliquus. Folia Microbiol 51(4):342-348

Chisti Y (2007) Biodiesel from microalgae. Biotechnol Adv 25 (3):294-306

Chisti Y (2008) Biodiesel from microalgae beats bioethanol. Trends Biotechnol 26(3):126-131

Cooksey K, Guckert J, Williams S, Callis P (1987) Fluorometric determination of the neutral lipid content of microalgal cells using Nile red. J Microbiol Meth 6(6):333-345

Cunningham J (2007) Biofuel joins the jet set. Prof Eng 20(10):32-32

Dukes J (2003) Burning buried sunshine: human consumption of ancient solar energy. Climate Change 61(1):31-44

Elsey D, Jameson D, Raleigh B, Cooney M (2007) Fluorescent measurement of microalgal neutral lipids. J Microbiol Meth 68 (3):639-642

Gouveia L, Oliveira A (2009) Microalgae as a raw material for biofuels production. J Ind Microbiol Biotechnol 36(2):269-274

Greenwell H, Laurens L, Shields R, Lovitt R, Flynn K (2010) Placing microalgae on the biofuels priority list: a review of the technological challenges. J Roy Soc Interface 7(46):703-726. doi:10.1098/rsif.2009.0322

Griffiths M, Harrison S (2009) Lipid productivity as a key characteristic for choosing algal species for biodiesel production. J Appl Phycol 21(5):493-507

Guckert J, Cooksey K (1990) Triglyceride accumulation and fatty acid profile changes in Chlorella (Chlorophyta) during high $\mathrm{pH}-$ induced cell inhibition. J Phycol 26(1):72-79

Guckert J, Cooksey K, Jackson L (1988) Lipid sovent systems are not equivalent for analysis of lipid classes in the microeukaryotic green alga, Chlorella. J Microbiol Meth 8(3):139-149

Hill J, Nelson E, Tilman D, Polasky S, Tiffany D (2006) Environmental, economic, and energetic costs and benefits of biodiesel and ethanol biofuels. Proc Natl Acad Sci USA 103(30):11206-11210

$\mathrm{Hu}$ Q, Sommerfeld M, Jarvis E, Ghirardi M, Posewitz M, Seibert M et al (2008) Microalgal triacylglycerols as feedstocks for biofuel production: perspectives and advances. Plant J 54(4):621-639

Khlebovich V, Degtyarev A (2005) Mechanism of defensive morph formation in Scenedesmus acutus (Chlorophycea, Scenedesmaceae). Dokl Biol Sci 403(1-6):303-305

Lardon L, Hel̀lias A, Sialve B, Steyer J-P, Bernard O (2009) Lifecycle assessment of biodiesel production from microalgae. Environ Sci Technol 43(17):6475-6481

Lee S, Yoon B-D, Oh H-M (1998) Rapid method for the determination of lipid from the green alga Botryococcus braunii. Biotechnol Tech 12(7):553-556
Lee J-Y, Yoo C, Jun S-Y, Ahn C-Y, Oh H-M (2010) Comparison of several methods for effective lipid extraction from microalgae. Bioresour Technol 10(1, Supplement 1):S75-S77

Li Y, Horsman M, Wang B, Wu N, Lan C (2008) Effects of nitrogen sources on cell growth and lipid accumulation of green alga Neochloris oleoabundans. Appl Microbiol Biotechnol 81 (4):629-636

Makulla A (2000) Fatty acid composition of Scenedesmus obliquus: correlation to dilution rates. Limnologica 30(2):162-168

Mandal S, Mallick N (2009) Microalga Scenedesmus obliquus as a potential source for biodiesel production. Appl Microbiol Biotechnol 84(2):281-291

Nichols H, Bold H (1965) Trichosarcina polymorpha gen. et sp. nov. J Phycol 1(1):34-38

Pickett-Heaps J, Staehelin L (1975) The ultrastructure of Scenedesmus (Chlorophyceae). II. Cell division and colony formation. J Phycol 11:186-202

Schenk P, Thomas-Hall S, Stephens E, Marx U, Mussgnug J, Posten C et al (2008) Second generation biofuels: high-efficiency microalgae for biodiesel production. BioEnergy Res 1(1):20-43

SERI (1986) Microalgae culture collection 1985-1986 (M. T. R. Group, Trans.). Solar Energy Research Institute, Golden, p 100

Sheehan J, Dunahay T, Benemann J, Roessler P (1998) A look back at the United States Department of Energy's aquatic species program-biodiesel from algae. National Renewable Energy Laboratory, Golden, p 328

Shen Y, Pei Z, Yuan W, Mao E (2009) Effect of nitrogen and extraction method on algae lipid yield. Int J Agric Biol Eng 2 (1):51-57

Shen Y, Yuan W, Pei Z, Mao E (2010) Heterotrophic culture of chlorella protothecoides in various nitrogen sources for lipid production. Appl Biochem Biotechnol 160(6):1674-1684

Shifrin NS, Chisholm SW (1981) Phytoplankton lipids: interspecific differences and effects of nitrate, silicate, and light-dark cycles. J Phycol 17:374-384

Stephenson A, Dennis J, Howe C, Scott S, Smith A (2010) Influence of nitrogen-limitation regime on the production by Chlorella vulgaris of lipids for biodiesel feedstocks. Biofuels 1:47-58

Stumm W, Morgan J (1996) Aquatic chemistry, 3rd edn. Wiley, New York

Thielmann J, Tolbert NE, Goyal A, Senger H (1990) Two systems for concentrating $\mathrm{CO}_{2}$ and bicarbonate during photosynthesis by Scenedesmus. Plant Physiol 92:622-629

Trainor F, Cain J, Shubert L (1976) Morphology and nutrition of the colonial green alga Scenedesmus: 80 years later. Bot Rev 42 (1):5-25

Wiltshire K, Boersma M, Möller A, Buhtz H (2000) Extraction of pigments and fatty acids from the green alga Scenedesmus obliquus (Chlorophyceae). Aquat Ecol 34(2):119-126

Yang Y, Gao K (2003) Effects of $\mathrm{CO}_{2}$ concentrations on the freshwater microalgae, Chlamydomonas reinhardtii, Chlorella pyrenoidosa and Scenedesmus obliquus (Chlorophyta). J Appl Phycol 15(5):379-389 